\title{
DESCARTES: LA FÁBULA DEL MUNDO Y LA CERTEZA MORAL
}

\author{
Daniel Gamper Sachse \\ (Universitat Autónoma de Barcelona)
}

A lo largo de lo que sigue se quiere hacer una lectura radical de algunos fragmentos de la obra de Descartes, precisamente de aquellos que más cuestionan el cartesianismo de Descartes. Los engranajes de esta "lectura radicalizada" son la "fábula del mundo" y el concepto de certeza moral.

El método cartesiano en Los Principios de la Filosofía y El . Mtundo deja de lado el ámbito de la especulación metafísica propio de El Discurso del . Método y se adentra en el ámbito de lo lipotético. A partir de ahora el método matemático-deductivo es aplicado para explicar los fenómenos de la luz o del magnetismo, se tratará en adelante de lingir o imaginar hipótesis que respeten las leyes del entendimiento, es decir, que presenten una realidad estructurada racionalmente.

Asi, pues, Descartes introduce una hipótesis, un fingimiento,' que no puede ser interpretado únicamente como movimiento defensivo frente la intolerancia eclesiástica (lésse Galileo) sino que es consecuente con la concepción del hombre como ser finito, capaz tan sólo de afirmaciones finitas, indefinidas. Así, por ejemplo, en El Mfundo,

mi proyecto no es el de explicar las cosas que existen efectivamente en el verdadero mundo, sino sólo fingir uno a mi gusto, en el que nada haya que los espirikus más comunes no puedan concebir y que pueda, no obstante, ser creado tal como lo habre fingido?

Sin embargo, el carácter hipotético-deductivo de la propuesta cartesiana, en contraposición con la ciencia inductiva y cualitativa del Renacimiento, no puede ser atribuido únicamente a la condición finita del saber humano, sino que los prinicipios asi fingidos son los fundamentos del pensamiento humano, es aquello inamovible y universal ${ }^{3}$ en el entendimiento. De ahi, que sea irrelevante para Descartes si fingimos o no un mundo, ya que sea éste como sea, la ciencia, el entendimiento, sólo lo podra leer en téminos matemáticos. (Hasta aqui una reconstrucción respetuosa con la autocomprensión de Descartes).

En un primer momento, Descartes postula unos principios claros y evidentes para el entendimiento, y a continuación se fingen unas hipótesis que aunque fàlsas (es decir, opuestas a lo afirmado por las Sagradas Escrituras) son útiles parn "salvar los fenómenos". Sin embargo, los resultados que se deducen de estas hipótesis siguiendo los principios de la matemática poseen un carácter ambiguo, que se expresa mediante la distinción al final de Los Principios entre, de una parte, la "certeza moml" $y$, de la otra, una certeza superior a csta alianzada en Dios comno "soberano bien y fuente de toda verdad". La certeza moral es ejempliticada como sigue:

Si alguien interesado en conocer el contenido de un escrito cifrado, redactado con letras ordinarias, lee una $B$ cuantas veces aparezca tina $A, y$ asimismo, lee una $C$ cuantas veces apartece una $B, y$ sustituye para efectuar su descitramiento a cada letra por la letra gute la sigue en el alfabeto; si leyendo de esta fonma haya

I DESCARTES, Los Principios ale la filosofia, (Madrid, trad. Guillermo Quintós) Parte Tercera. ant. 1 y 2.

2 DESCARTES, El mumlo. Tratudo de la hus, Barcelona 1989, cap. VI, p. 107 (trad. Salvi Turri). Ver tainbién Los Principios. Parte Tercera, arts. 44 y 15.

3 "... todo lo que laysa dicho os parecerd tan bien probado que juzgaréis que un hombre de buen ingenio, inc. lluso aunque bubiera sido crijdo en un desierto $y$ no hubiera tenido nunca otra luz yue la de la naluraleza, no podria tener otras razones más que las nuestras". "Investigación de la verdad" en Meditaciones Metafisicas y otros textos, Madrid 1987, p. 98 (trad. E. López y M. Graha). 
palabras que tengan sentido, no dudará que sea el verdadero sentido de este escrito el que ha encontrado, aun cunndo el que lo hubiese escrito, hay atribuido otro totalmente distinto al dar otra signilicación a cada letra (...). Asi pues, si se considera cuan diversas propiedades del imán, del fuego y de todas las otras cosas qua hay en el mundo, han sido muy evidentemente deducidas de un pequeño nummero de causas que he propuesto al principio de este tratodo, aun cuando se haya imaginado que las he supuesto por azar y sin cute la razón me haya perstadido de elias, no se dejara por ello de tener, al menos, tanta mzón para juzgar que son las verdaderas cousas de lo que he daducido, como la hay para creer que se ha hallado el verdadero sentido de un escrito cifrado cuando se ve que se sigue de la significación que, por conjetura, se ha dado a una letra. ${ }^{+}$

El concepto de certeza moral nos remite al estatuto de verdad de los principios, de los cinientos sobre los que Descartes edifica su fisica. Descartes, como varias ponencias han mostrado a lo largo del Congreso, 5 otorga un estatuto ambiguo a estas verdades. De una parte afirma el carácter eterno y universal de estas verdades y, de la otra, constata el enraizamiento de éstas en la razón humana, es decir, constata la contingencia, no divinidad, de las afirmaciones fundamentales de la fisica. Quizá a riesgo de deformar la pretensión transcedental del proyecto cartesiano, quisiera decantarme por la segunda concepción de la verdad de los principios, a saber, el entendimiento finito humano como origen único de la fisicil cartesiana.

Esta concepción, ciertamente psicologista y relativista de las "verdades eternas" cartesianas, toma como modelo a Dios garante ínicamente de su propia existencia, causa sui, ésta si "verdad eterna no contingente"; pero es un Dios que no garantiza el carácter absoluto de los cimientos de la ciencia. Por ejemplo, la negación de la teoria atomista que implicaria la indivisibilidad de la materia, este principio fundamental del entendimiento humano no es una verdad eterna, desde el momento en que Dios hubiera podido hacer posible lo que para nosotros es imposible. ${ }^{6}$ De tal manera que la verdad de los principios no procede de la garantia externa, es decir de Dios, sino de la percepción clara y distinta de la verdad de estos principios.

Aqui es donde cobra sentido la "certeza moral", la cual aunque es contrapuesta a una certeza superior a ella, ejemplitica el modelo de ciencia utilitarista y consciente de las limitaciones del esquerna conceptual o de la ontología sobre la que se fundamenta. La comparación en la cita de la Parte Cuarta de Los Principios que he lejdo anteriormente entre la decodificación de un texto y el funcionamiento de una teoria, muestra claramente la deflación de la realidad de las cosas (del texto) en pro de los principios que hemos decidido tomar como verdaderos (el código que utilizamos para descifrar el texto). Esta comparación es introducida por Descartes con el fin de ilustrar la esencia utilitarista de la ciencia, la cual no persigue tanto una interpretación correcta de la realidad, como una explicación de ésta en términos que nos permitan interactuar con las cosas, que nos permitan progresar en la tarea de dominación de la naturaleza. La certeza moral, principio rector de la ciencia, puede ser identificada, en esta lectura provisional, de manera que asi como en el concepto de una moral provisional Descartes introduce una idea ni clara ni distinta, a saber, las convenciones sociales, como aquello que no debe ser puesto en duda y que debe ser conservado para la mejor convivencia hasta que se pueda fundamentar una moral sobre bases más sólidas; igualmente la certeza moral de las ciencias posee un rasgo de provisionalidad, es decir de aquello que debemos presuponer aunque no estemos seguros de su valor absoluto y que, dentro de una concepción procesual de la ciencia, puede ser verificado, mejorado o condenado cuando se alcance un mayor grado de saber, en camino al "último grado de la sabiduria".

4 DESCARTES, Los Principios de la flosofia, Tercera Parte, art. 205.

5 Véase la conferencia de Enrique Romerales ¿l'erdades eternas contingentes?

6 Como muestra la "Leture a Miesland" del 2 de Mayo de 1644 (?) en A. T. IV, pp. 118-119. (le agradezco la localización de la cita a Jesús Hernández). 